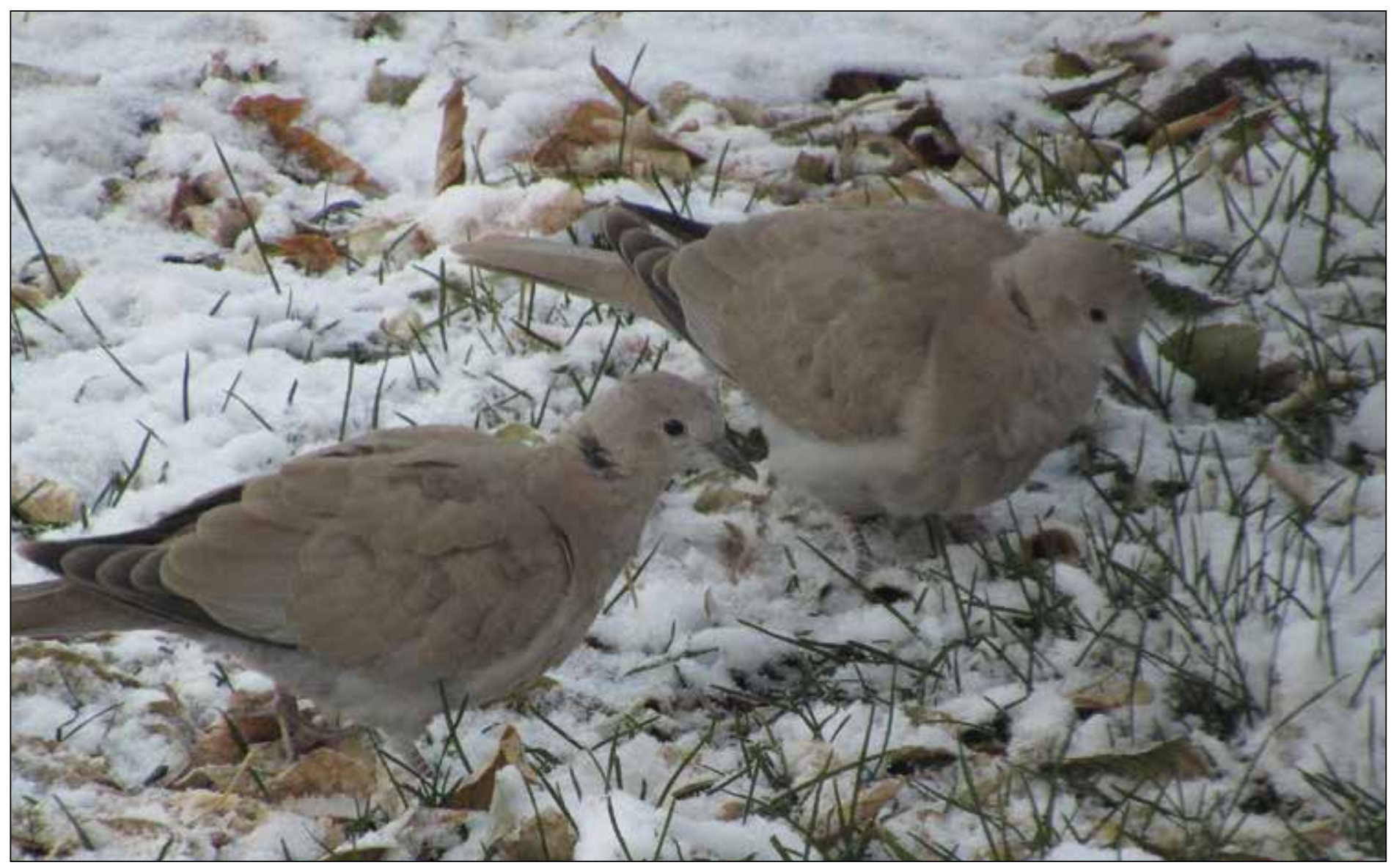

Eurasian Collared Doves. All photos courtesy of Donna Firby Gamache.

\title{
EURASIAN COLLARED-DOVE: INVADER SPREADS ACROSS THE WEST
}

Donna Firby Gamache

Box 453

MacGregor, MB ROH ORO

lucgam@mymts.net

Alien invaders in your backyard? Last winter I saw three from my window, and I was pleased to see them, for they weren't from outer space. Instead, these invaders were Eurasian Collared-Doves (Streptopelia decaocto), which are spreading across the United States (except in the New England area) and southwestern Canada.

I first saw these three doves in my yard at the beginning of February 2018 and they visited all winter, usually feeding on the ground under our sheltered bird feeder. On cold winter days, they rested in the sun or on the nearby wooden fence.

The Eurasian Collared-Dove first arrived in the New World in the 1970s. Some were brought as pets to the Bahamas where some escaped from a pet store, while others were deliberately set free. By the 1980s, they had reached south Florida and from there began their spread in a north-westerly direction across the U.S. (apparently avoiding the northeast part of the U.S.).

They became the fastest-spreading invasive avian species known so far. These doves have now been sighted all the way to Alaska. They are one of the great colonizers of the world, having previously spread from southeast Asia throughout Europe.

While the three birds I saw last winter provided my first sighting of Eurasian Collared-Doves in

MacGregor, Manitoba, birders had reported them in nearby Portage la Prairie for the previous two years during both summer and winter. The collared-doves were present in my yard all last winter and three or four stayed over the summer. Although I did not locate a nest, frequent sightings of a pair in spruce trees two houses away convinced me that they were nesting there. We also heard their distinctive calls often, particularly in the evening. By late summer, four or five were frequently seen on hydro wires and fences.

Information from the Atlas of the Breeding Birds of Manitoba indicates that the Eurasian Collared-Dove was officially added to the Manitoba bird list in May 2003, when a bird 


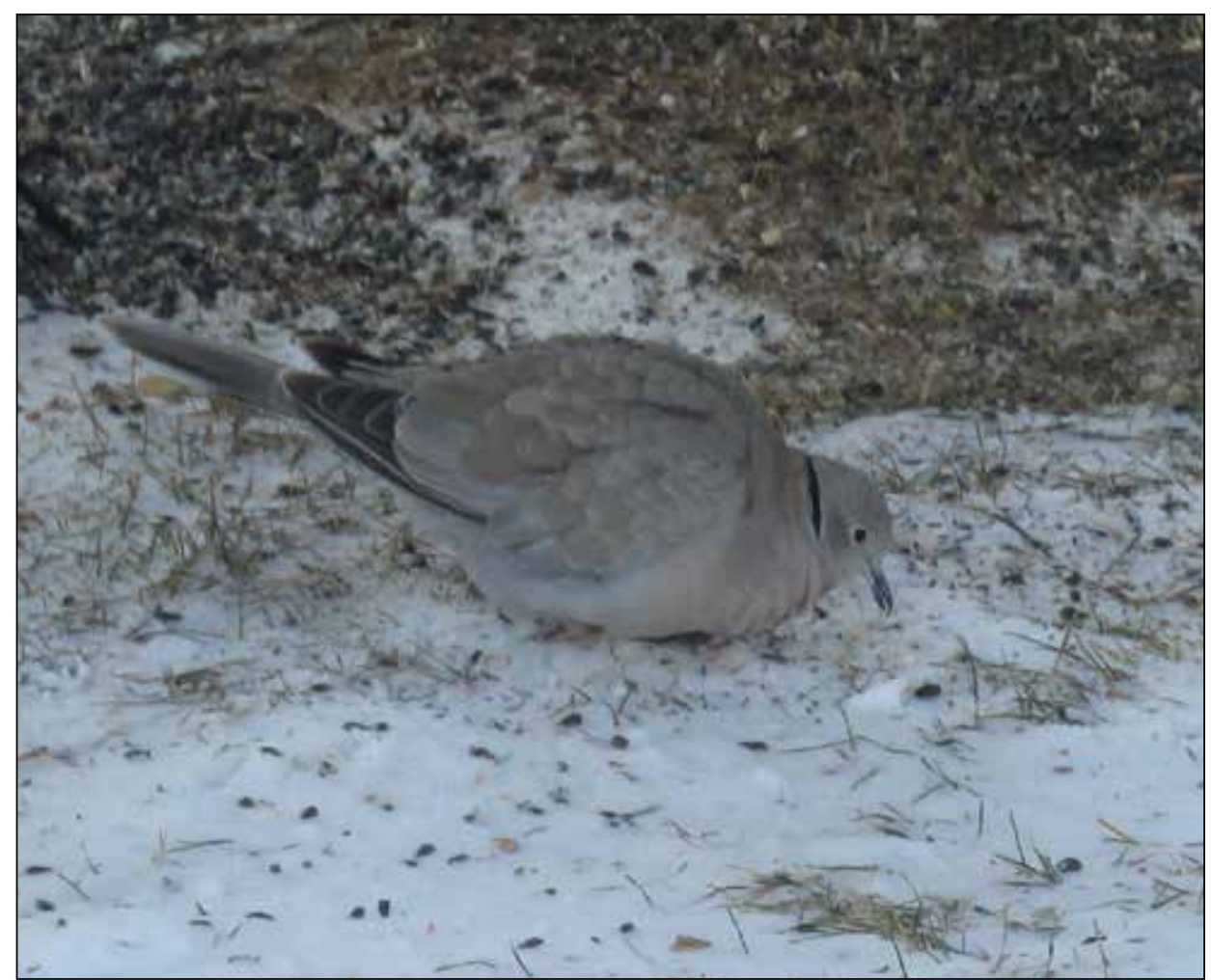

was present in Holland. ${ }^{1}$ In the years when the atlas was compiled (20102014), the species was counted in 22 squares ( $2 \%$ of the Prairie Potholes), all from the Red River valley west and mostly within $100 \mathrm{~km}$ of the U.S. border. Since then, there have been increased populations in a few spots, such as Portage la Prairie and Glenboro. In other areas, the birds have disappeared. A few southern Saskatchewan towns such as Weyburn and Mortlach "have generally reported robust populations". The largest Christmas Bird Count tally in that province was 116 at Moose Jaw in 2009. ${ }^{2}$ The first records, for Saskatchewan as well as Canada as a whole, were at Langham and Last Mountain Bird Observatory in 1998. ${ }^{2}$

The most recent unofficial information available so far from the Manitoba 2018 Christmas Bird Count shows Eurasian Collared-Doves in only a few counts, but a surprising number of birds (45) were counted in Cypress River on December 21, as reported by Ken de Smet (apparently one birder there is feeding at least 35 on a regular basis). Slightly larger and chunkier than our native Mourning Dove (Zenaida macroura), the collared-dove is grayish-beige, with a narrow, black half-collar edged with white around the back of the neck (see photos). In juveniles, this collar is sometimes less noticeable. The undertail is largely white, especially visible when it flies, and the wings are dark-tipped. It lacks the black spots common on the wings and sides of the Mourning Dove.

The collared-dove's call is a three-syllable coo-COO-coo, shorter and repeated more frequently than Mourning Doves, often five to 12 times in a row (by contrast, the Mourning Dove's call is usually five syllables: coo-ah, coo, coo, CoO, with longer intervals in between calls). Collared-doves are ground feeders and, unlike native doves, do not migrate, so in winter they frequent yards with birdfeeders, or farmyards.

Some bird-lovers fear the Eurasian Collared-Dove might have a negative impact on Mourning Doves in the same way as the House Sparrow (Passer domesticus) and the

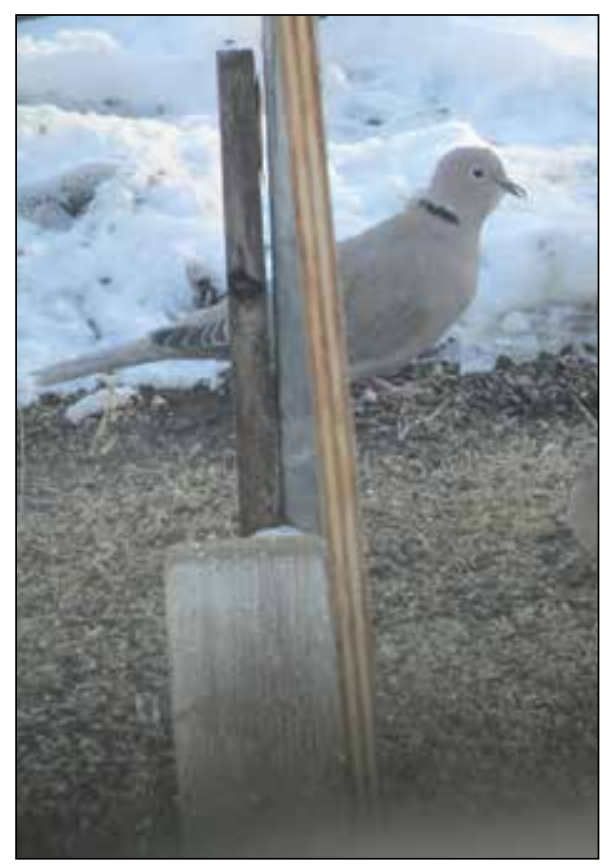

European Starling (Sturnus vulgaris) have been blamed for decreases in native songbirds. But so far research indicates that the native population actually seems to be greater when they coexist with collared-doves. A 2010 study found that in North America, the site-level abundance of four other dove species all increased with Eurasian Collared-Dove abundance throughout that study's sampling period, 1999-2008. ${ }^{3}$

Watch for this new 'invader' in your own area. For more information and pictures, see:

https://www.allaboutbirds.org/guide/ Eurasian_Collared-Dove/id

1. Koes RF, Parsons RJ (2018). Eurasian Collared-Dove in Artuso C, Couturier $A R$, De Smet KD, Koes, RF, Lepage D, McCracken J, Mooi R, Taylor P (Eds). Atlas of the Breeding Birds of Manitoba, 2010-2014. Bird Studies Canada. Winnipeg, Manitoba. http://www. birdatlas.mb.ca/accounts/speciesaccount. jsp?sp=ECDO\&lang=en [04 Jan 2019]

2. Smith AR, Houston CS, Roy F (Eds) (2019). Birds of Saskatchewan. Nature Saskatchewan.

3. Bonter DN, Zuckerberg B, Dickinson JL. 2010. Invasive birds in a novel landscape: habitat associations and effects on established species. Ecography 33: 494-502. 